\title{
Developing Sustainable Cowpea Seed Systems for Smallholder Farmers through Innovation Platforms in Nigeria: Experience of TL III Project
}

\author{
Teryima lorlamen, Lucky O. Omoigui, Alpha Y. Kamara, \\ Umar Garba, Nater lyorkaa, Temitope Ademulegun, \\ and Reuben Solomon
}

\begin{abstract}
Limited access to and low use of quality seed of improved varieties rank among the topmost causes of persistently low cowpea yields in Nigeria. This paper presents experiences under the Tropical Legume III (TL III) project in facilitating the access of smallholder farmers to seeds of improved cowpea varieties through the establishment of innovation platforms (IPs) that were introduced in 2015 as part of the activities of the TL III project. There was rapid adoption and use of newly released varieties by farmers as a result of increased awareness of improved varieties through multi-media and user-friendly communication strategies and tools. During the four years of the project (2015-2018), a total of seven multistakeholder platforms (MSPs), which comprised six seed companies, 46 farmer groups, five public seed enterprises, two NGOs, and 718 individual seed entrepreneurs and other stakeholders, were established/strengthened to link actors in the cowpea value chain. Community-based seed producers were linked to seed companies while seed companies were linked to research institutions to access early generation seed (EGS). These activities led to the production of over 532 tons of basic seed and 8366 tons of certified/QDS seed of improved cowpea varieties that were entrenched in the seed system. Yield also increased almost two-
\end{abstract}

T. Iorlamen $(\bowtie) \cdot N$. Iyorkaa

Federal University of Agriculture Makurdi, Makurdi, Nigeria

L. O. Omoigui · T. Ademulegun

International Institute of Tropical Agriculture, Kano, Nigeria

A. Y. Kamara · R. Solomon

International Institute of Tropical Agriculture, Ibadan, Nigeria

U. Garba

Kano State Agricultural and Rural Development Programme, Kano, Nigeria

(C) The Author(s) 2021

E. Akpo et al. (eds.), Enhancing Smallholder Farmers' Access to Seed of

Improved Legume Varieties Through Multi-Stakeholder Platforms,

https://doi.org/10.1007/978-981-15-8014-7_9 
fold from 500 to $900 \mathrm{~kg} / \mathrm{ha}$ on farmers' field. Women and youth incomes increased as a result of seed entrepreneurship activities. The small packs approach was an efficient and cost-effective means of reaching more farmers with affordable quantities of seed and a wide range of preferred varieties.

\section{Keywords}

Cowpea · Seed systems · Multi-stakeholder platform · Early generation seed (EGS)

\subsection{Introduction}

Approximately $90 \%$ of the world's cowpea is grown in sub-Saharan Africa, most of which is in West Africa particularly in Nigeria (FAOSTAT 2017). Nigerian agriculture, as in other developing countries, is confronted with an actual problem of productivity. Smallholder farmers face multiple challenges that impede cowpea production and productivity because cowpea cultivation is mainly under traditional systems, with low grain yield (400-450 kg/ha) in farmers' field. The low yield is attributed to severe attacks of pest complexes, diseases, low soil fertility, drought, poor agronomic practices, and limited access to improved seed. Among these constraints, limited access to and low use of quality seed of improved cowpea varieties by farmers rank topmost among constraints leading to persistent low yields among smallholder farmers. Over the years, national and international centers have developed several improved cowpea varieties that are resistant to most of the production constraints, but very few made their way to the farmers' fields on account of weak seed systems. Due to limited commercialization of cowpea varieties by the private seed sector, the cowpea seed system has remained underdeveloped and weak, resulting in a large seed gap. The private sector, on the other hand, is not interested in investing in cowpea seed production because of the perceived weak market outlet and low returns on investment. This then calls for strategies to catalyze sustainable supply while imparting knowledge and skill in the production and marketing of cowpea between released varieties and those available at community level for farmer use.

Given the existing evidence and this caveat, strategies were developed to create opportunities among the different actors and identify their roles in the cowpea value chain that could stimulate more demand for improved cowpea seed. The actors include farmer cooperatives, traders, processors, women groups, seed companies, individual entrepreneurs, research institutes, grain aggregators, and agro-dealers

The Tropical Legumes III (TL III) project funded by the Bill \& Melinda Gates Foundation was a major leap towards achieving sustainable cowpea seed systems that will meet the needs of different categories of farmers. One of the key pillars of the TL III project was the establishment and utilization of multi-stakeholder platforms as fora for skill and knowledge enhancement, in linking legume value chain actors, as well as enhancing efficiency and effectiveness in technology promotion and dissemination for increased access by smallholder farmers to quality seeds of 
improved cowpea varieties. The platform also provided avenues for training, skill enhancement of members, and enhancing efficiency and effectiveness in technology development, promotion, and use. Seed systems stakeholders, including national partners, private seed companies, small seed producers, and farmer-based seed producing units were trained on seed catalogue and digital seed roadmap to build their skills in planning, producing, tracking, and delivering quality seeds to smallholder farmers in Nigeria. The objective of the IP was, therefore, to strengthen linkages among various cowpea seed value chain actors to catalyze sustainable production and supply of quality seeds of improved cowpea varieties to smallholder farmers in Nigeria.

\subsubsection{Establishment, Membership, and Composition of the Platforms}

\subsubsection{Overall Process of the Platform Establishment}

According to Tukahirwa et al. (2013), IPs serve as a forum to facilitate interactions and learning among stakeholders with a common challenge to address. The joint efforts of the stakeholders led to participatory diagnosis of problems-joint exploration of opportunities and investigation of solutions that will lead to promotion of innovation. In most of the communities, the process of establishing MSPs started with the formation of a small interest group composed of individuals with like minds to strengthen their agricultural activities. The IPs consisted of a local community village, women leaders, researchers, and development agents. Each IP elected its own leader, who was responsible for (1) registration of interested members, (2) organizing meetings and field visits in the absence of researchers or development workers, and (3) monitoring the implementation of agreed farm schedules. Local by-laws were formulated to ensure equal and sustained participation, although their effectiveness was constrained by the existence of close relationships among IP members and weak enforcement mechanisms.

A sustainable cowpea production arrangement begins with the production of quality seed at the farm level and good participation of all the actors involved. TL-III's strategy for improving access to improved seed was based on establishing a MSP. This was designed to ensure the active participation of all the major stakeholders in the cowpea value chain in each community together with researchers, NGOs, farmers, extension agents, and the private and public sectors in the identification and prioritization of local problems and their solutions. Major problems identified during community mobilization activities were declining soil fertility, the parasitic weed Striga, crop pests, poor access to improved seed, high price and unavailability of fertilizer, and lack of credit. An agreement was reached to give priority attention to these problems.

During planning activities, local MSPs were identified and, in some cases, new ones formed to formulate and implement action plans to overcome identified problems. This involved the selection of leaders by each group, who would be responsible for testing and sharing experiences on the new technologies. Subsequently 
each leader worked closely with other farmers within the same platform group to support their use of new technologies and at the same time, help to ensure that improved cowpea varieties were properly introduced. Individuals were identified by each group to be trained as community seed producers. The seed produced under this arrangement was tagged "informal seed production" that does not require rigorous supervision by the National Agricultural Seed Council (NASC). The communitybased seed production scheme was for local use under the supervision of extension agents and the TL-III team. Other farmers were identified to produce certified seeds under the supervision of NASC officers, who were also members of the platform. To help the farmers to produce or to buy the cowpea, the majority of them were linked to private seed companies and financial institutions to facilitate access to credit at low interest rates.

A number of initiatives aimed at supporting and empowering women were also identified. These included:

- Support to women farmer groups, female-led farmers, and female seed producers.

- Support for postharvest activities for cowpea processing and utilization.

After that, 20 women per MSP were identified to produce community seeds. There were also specific efforts to ensure the inclusion of youth to guarantee creating a cradle of informed future farmers (Table 9.1).

Table 9.1 Establishment and composition of the innovation platforms

\begin{tabular}{l|l|l|l|l|l}
\hline Innovation platform & $\begin{array}{l}\text { Year } \\
\text { established }\end{array}$ & $\begin{array}{l}\text { Membership at } \\
\text { establishment }\end{array}$ & $\begin{array}{l}\text { Current } \\
\text { membership }\end{array}$ & $\begin{array}{l}\text { No. and } \\
\% \\
\text { women }^{\mathrm{a}}\end{array}$ & $\begin{array}{l}\text { No. and } \\
\% \\
\text { youth }^{\mathrm{b}}\end{array}$ \\
\hline Dawakin Tofa & June 2014 & 225 & 300 & $60(20)$ & $130(43)$ \\
\hline Makoda & June 2018 & 225 & 270 & $45(17)$ & $100(37)$ \\
\hline Tsanyawa & July 2015 & 225 & 300 & $75(25)$ & $80(27)$ \\
\hline $\begin{array}{l}\text { Bichi-Rano } \\
\text { farmers' association }\end{array}$ & June 2017 & 150 & 210 & $31(15)$ & $79(38)$ \\
\hline $\begin{array}{l}\text { Sule-tankarkar } \\
\text { cowpea producers } \\
\text { association }\end{array}$ & May 2014 & 69 & 115 & $13(11)$ & $55(48)$ \\
\hline $\begin{array}{l}\text { Ukange-Ukpam } \\
\text { cowpea and } \\
\text { soybean farmers } \\
\text { association }\end{array}$ & June 2013 & 65 & 160 & $62(39)$ & $60(38)$ \\
\hline $\begin{array}{l}\text { Ucha-Abwa cowpea } \\
\text { producers } \\
\text { association }\end{array}$ & April 2016 & 85 & 200 & $104(52)$ & $110(55)$ \\
\hline
\end{tabular}

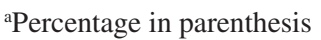

'Youth is under 35 years of age 


\subsection{The Different Categories of Stakeholder Members of the Platform}

The categories of the stakeholder members in the IPs comprised CBSOs/seed companies, farmers, agro-dealers, research institutions, state agricultural research projects, contract sprayers, and grain merchants (Table 9.2).

\subsection{Platform Governance Structure (Steering Committee and Arrangements in Place to Facilitate Smooth Implementation of Platform Activities)}

During the establishment of the platform, the stakeholders were trained on the importance of setting up the IP, how it will function, the prospects of cowpea seed production, and best production practices using the latest technologies/products delivered by research institutes. Stakeholders were encouraged to work together to achieve a robust and rewarding cowpea seed industry. After setting up the IPs, the members elected leaders to effectively run the affairs of the IP. A chairman and secretary were appointed to coordinate the activities of the IP and interface with other stakeholders when necessary. They will also disseminate information to members and organize meetings to deliberate on matters.

\subsubsection{Composition, Roles, and Responsibilities of the Platform Members}

The MSP is composed of diverse stakeholders including farmers, input dealers, transporters, seed regulatory agency, service providers, financial institutions, extension agents, research institutions, policy makers, and grain merchants/retailers/consumers. Their roles and responsibilities are presented in Table 9.3.

Table 9.2 Number of individuals per representatives per category

\begin{tabular}{l|l}
\hline Categories of members & Number of representative persons at the establishment \\
\hline Chairman & 1 \\
\hline Farmers & 300 \\
\hline Traders & 12 \\
\hline Processors (all women) & 12 \\
\hline Research institutes & 3 (IITA, IAR, UAM) \\
\hline CBOs & 15 \\
\hline Media & 4 \\
\hline Grain off-takers & 2 (Dawanau market) \\
\hline Seed companies & 5 (Maina seeds, Greenspore, Happy seed, AU saye, and Seed project \\
\hline $\begin{array}{l}\text { Agrochemical } \\
\text { company }\end{array}$ & 3 \\
\hline
\end{tabular}


Table 9.3 Roles and responsibilities of different stakeholders in innovation platform

\begin{tabular}{|c|c|}
\hline Stakeholders & Roles and responsibilities \\
\hline Farmers & $\begin{array}{l}\text { Problem identification, indigenous knowledge, development of } \\
\text { solution, testing and evaluation of solutions, and adoption of } \\
\text { solutions }\end{array}$ \\
\hline Service providers & $\begin{array}{l}\text { Hired contract sprayer to protect the cowpea being produced by the } \\
\text { outgrowers, seed producers, and other individual farmers' }\end{array}$ \\
\hline Input dealers & Timely delivery of quality and affordable inputs/information \\
\hline $\begin{array}{l}\text { National Agricultural } \\
\text { Seed Council (NASC) }\end{array}$ & $\begin{array}{l}\text { Register all seed producers, supervise seed production of all seed } \\
\text { classes produced by private and public seed companies for quality } \\
\text { control }\end{array}$ \\
\hline Private companies & Production and marketing of certified seed \\
\hline Farmer groups & Engaged in informal seed production especially at the grassroot level \\
\hline $\begin{array}{l}\text { Transporters and other } \\
\text { services }\end{array}$ & Guarantee timely service provision \\
\hline Financial institutions & Develop financial products/services that support interventions \\
\hline Extension agents & $\begin{array}{l}\text { Provide information on identification, development, and } \\
\text { implementation of projects }\end{array}$ \\
\hline Research institutions & $\begin{array}{l}\text { Critical problem analysis, provide solution to the problem, conduct } \\
\text { new research where necessary. Production of early generation seed } \\
\text { (breeder and foundation seeds) }\end{array}$ \\
\hline Policy makers & $\begin{array}{l}\text { Mobilization of farmers, support formulation of appropriate policies } \\
\text { and policy advocacy }\end{array}$ \\
\hline Merchant/retailer & $\begin{array}{l}\text { Procurement of grains produced by farmers. Feedback on perception } \\
\text { and consumer behavioral change }\end{array}$ \\
\hline Media & Dissemination of information \\
\hline
\end{tabular}

Platform Governance and Decision-Making The leadership of the platform comprises the Chairman, Vice Chairman, Secretary, Assistant Secretary, Financial Secretary, and Treasurer that run the activities and administration of the MSP in order to facilitate smooth implementation of platform activities.

\section{The leaders ensure the following:}

- Dialogue and promote understanding among stakeholders and provide an avenue for them to create a common vision and mutual trust.

- Enable partners to identify the bottlenecks hindering innovation and develop solutions beyond what individual actors can achieve alone.

- Create motivation and a feeling of ownership of the solutions that members have developed.

- Facilitate upward communication which enables weaker actors (such as smallscale farmers) to express their views on an equal basis with the more powerful actors. 


\subsubsection{Facilitation of Platform Activities, Including Meetings}

The MSP members met at least once a month to discuss the focal areas and identify challenges and opportunities. To enhance stakeholder participation, especially for the weak ones, the platform developed a constitution that governed its operations. It had rules, regulations, and by-laws that were followed especially during meetings and other engagements of the members. Ground rules were normally spelled out during meetings to ensure that each participant had equal opportunities to participate actively in the deliberation of affairs. This was necessary to minimize marginalization of the weak, especially women and youth. In addition, the TL III project team held at least two meetings with MSPs, three times in a year: the first in February (in-house stakeholders meeting) to evaluate previous season cowpea production activities, the second (May-June) was to plan the activities of the next rainy season and provide pre-season trainings to the new producers. The third meeting was during October-November on seed business skills particularly for the seed entrepreneurs.

\subsubsection{Platform Activities}

Training Having recognized the significance of capacity building of the MSP to achieve its objectives, the project organized and facilitated several capacity development activities for its MSP. The MSP members were trained in quality seed production techniques (foundation and certified seeds), GAPs, IPM, data collection, and postharvest processing and storage. Agro-dealers were trained to market cowpea seed through innovative marketing (sale of small seed packets; 0.25, 0.5, 1, 2, 5, 10 , and $20 \mathrm{~kg}$ ) to ensure that quality seed of the new varieties was made available to farmers at affordable prices. Through "training of trainers" workshops on the use of improved integrated production technologies, management practices were promoted to narrow yield gaps to enhance cowpea grain and fodder production. Demonstration of best varieties and IPM options were established to reduce yield losses in cowpea cultivation. Training on improved cowpea storage was organized in partnership with the PICS (Purdue Improved Cowpea Storage) project to promote safe storage of cowpea to reduce insect infestation. Processors were also trained on seed processing (cleaning, sorting, grading, and packaging), storage, and marketing. The repeated trainings of male/female farmers and seed producers in the proper management of cowpea production and management increased grain yields by over $50 \%$ over the four-year period compared with the yield levels prior to project intervention.

Seed Supply Research institutes (IITA, IAR, UAM) were responsible for producing early generation seeds (breeder and foundation seeds) of identified preferred varieties and making these available for foundation and certified seed production by the private seed companies. The seed companies produce foundation seeds with the 
research institutes also backstopping to meet the demand. The community-based organizations (CBOs) produce quality declared seed (QDS) with minimum supervision from the NASC to sell in their communities. The CBOs were linked to the private seed companies to access certified seed. This was to ensure that seed of the improved crop varieties was accessible to farmers in the remote areas. Individual men, women, and youth were also involved in seed production and acted as outgrowers to seed companies.

Popularizing New Varieties To create awareness on the availability of improved cowpea seed, various complementary awareness creation approaches were adopted. These included technology demonstrations, farmer field days, distribution of technology promotional materials (production guides, flyers, leaflets, and manuals), media (radio/TV programs, newspapers, and bulletins), and agri/seed fairs. Other activities facilitated include credit, introduction of machinery and farming equipment/labor-saving devices, and market development/developing linkages to facilitate collective marketing. All these awareness creation activities helped to stimulate the demand for the use of quality seed of improved cowpea varieties.

\subsubsection{Main Challenges Addressed by the Platform}

Some of the main challenges addressed by the platform were:

- Non-availability of quality seed to farmers particularly in the remote areas were overcome to a large extent through the promotion of community-based seed production (CBSP). The use of community-based seed production schemes has helped to produce and made available farmers preferred quality seed to farmers in the remote areas at affordable prices and also linked the seed producers to emerging markets. The market linkages encouraged seed producers to improve and increase their seed production.

- Input supplies: TL III improved access to fertilizer and agro-chemicals by linking farmers directly to independent village suppliers. This contributed to a reduction in their transaction costs and ensured that farmers had access to good quality fertilizer and agro-chemicals.

- Access to credit: Credit is a constraint in improving agricultural production and can only be accessed by those that have a proven production record, with the necessary bank deposits, and are credit worthy. Of concern is that to obtain credit, farmers are often faced with bureaucratic procedures and long waiting periods. To reduce transaction costs and waiting periods, TL-III strengthened MSPs and encouraged group members to open accounts and learn to save. Consequently, there has been great improvement in the provision of credit to farmers by microfinance banks. A change in the bank's strategy is to grant credit to farmer groups rather than individuals. This strategy before has favored women more than men as women groups are seen to be more trustworthy. 


\subsection{Achievements of the Platform}

Significant progress was made in addressing key problems of access to improved seed and other inputs. Before the Tropical Legume project started in 2007, access to good quality seed of cowpea varieties was a challenge to the smallholder farmers in Nigeria. To ensure that seed of the improved crop varieties was accessible to farmers, the project introduced a community-based seed production scheme. This integrated system allowed various actors to engage in the production of different seed classes (Fig. 9.1).

The NARS produced and made available, early generation seed (EGS), and breeder and pre-basic seed to the private seed companies for production of basic and certified seeds under close supervision by NASC. Two public institutions with mandate for genetic improvement of cowpea now produce EGS in Nigeria. The institution has their own seed unit with a revolving funds that guaranteed the unit financial autonomy.

The private seed companies then made available the basic/certified seed to local seed producers (individuals or groups supported by development partners such as farmer organizations).

These activities led to the cumulative production of over 532 tons of basic (foundation) seed and 8366 tons of certified/QDS seed of improved cowpea varieties which have been injected into the cowpea seed system in Nigeria in the last four years. Due to the strong partnerships supported by appropriate capacity building and availability of improved and end-user preferred varieties, seed production and

Availability and accessibility of various seed grades of newly improved and farmer demanded legume varieties in the target countries

1

Breeder seed (NARS \& Public and Private seed enterprises -licensed)

2

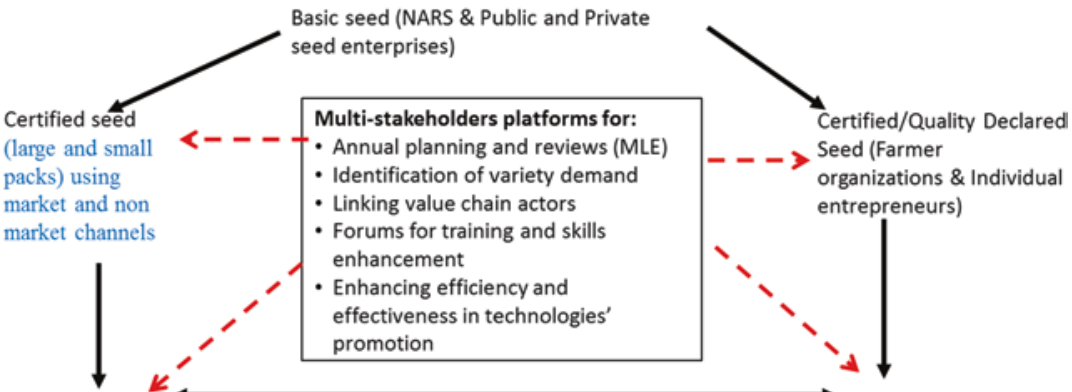

4

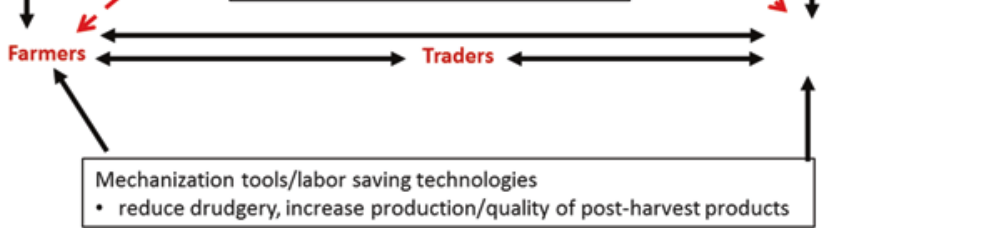

Fig. 9.1 Multi-stakeholder's platform for the seed delivery model 
supply were significantly increased. Thanks to community seed producers, the seed produced was available for smallholder farmers in remote areas. A large proportion of the cowpea varieties used to produce certified seed by farmers are still within 10 years of their release date.

Cowpea production in the projects from 2007 to 2019 showed an upward trend. For example, in Nigeria, seed production moved from 755 to 8366.3 tons within four years, representing about a $900 \%$ increase in production. Under TL-II and III, several new cowpea varieties (IT97K-499-35 [in 2008], IT89KD-288 and IT89KD-391 [in 2009], IT99K-573-1-1 and IT99K-573-2-1 [in 2011], IT07K-292-10 and IT07K-318-33 [in 2015], UAM09-1055-6 and UAM09-1051-1 [in 2016], IT07K-297-13 and IT08K-150-2 [in 2018]) were released in Nigeria. The number of farmers seeking improved cowpea varieties for planting has increased over the years. As a consequence, many private sector players (seed companies and individual entrepreneurs) are investing in the production and sale of quality seeds of improved varieties.

\subsubsection{Demonstration with Improved Varieties and Technologies}

Demonstration tests were set up in farmers' fields to compare improved varieties to farmers' local varieties. Field days were organized for farmers to appreciate and choose the best varieties at vegetative growth phase and at harvest time. From the activities conducted in all MSPs during the four years, improved varieties were always preferred by farmers. The yields of these varieties were superior to those of the local or previously released varieties.

During the four years of project implementation, significant progress was made towards achieving targets. A total of seven MSPs were established or strengthened to link actors in the cowpea value chain (seed producers, grain traders, researchers, extension staff, agro-dealers, and other input suppliers). Forty-two trainings and short courses were organized benefiting 13,220 (m: 10,416; f: 2804) platform members of which $21 \%$ were female. A total of 298 demonstrations, 10 field days, 29 media programs (electronic and print), and eight agri/seed fairs/exhibitions were organized to create awareness about improved cowpea varieties in the country.

\subsection{Achievement in Seed Production of Different Classes of Seeds}

The participation of several community seed producers and some private and public seed companies led to increased production of foundation, certified, or quality declared seed of cowpea, ensured farmers had access to improved seeds, and facilitated access to agricultural support services, particularly in the remote areas. Five organizations which comprised six seed companies, 46 farmer groups, five public seed enterprises, two NGOs, and 718 individual seed entrepreneurs were engaged in production and marketing of cowpea in Nigeria. These activities led to the 
cumulative production of 532.5 tons of basic (foundation) seed and 8366.3 tons of certified seed/QDS of improved cowpea varieties injected in the Nigerian seed sector. The projects ran in three phases: TL-II Phase I (20072011), TL-II Phase II (2012-2014), and Phase III or TL-III (2015-2019). The pragmatic effort witnessed a huge success in cowpea seed production and delivering of improved seed varieties to farmers (Fig. 9.2). The use of small packs was also successful in ensuring farmer access to improved cowpea varieties. Over 1600 tons of cowpea seed were sold using small packages representing about $20 \%$ of the total seed produced over the four-year period. The project facilitated the introduction of two labor-saving technologies/mechanization (planter and thresher) tools to reduce drudgery especially among female farmers.

There was also rapid adoption and use of newly released varieties by farmers as a result of increased awareness on improved varieties through multi-media and userfriendly communication strategies and tools. In addition, there was an increase in the number of channels and outlets that conveniently availed seed to farmers packaged in small, affordable packs.

\subsection{Achievements in the Areas of Access to New Markets, Finance Services, and Other Services}

The project also facilitated the use of small packs to enhance wider access to seed of improved varieties at affordable price. The use of small packs has been very successful in ensuring that many farmers have access to improved cowpea varieties.

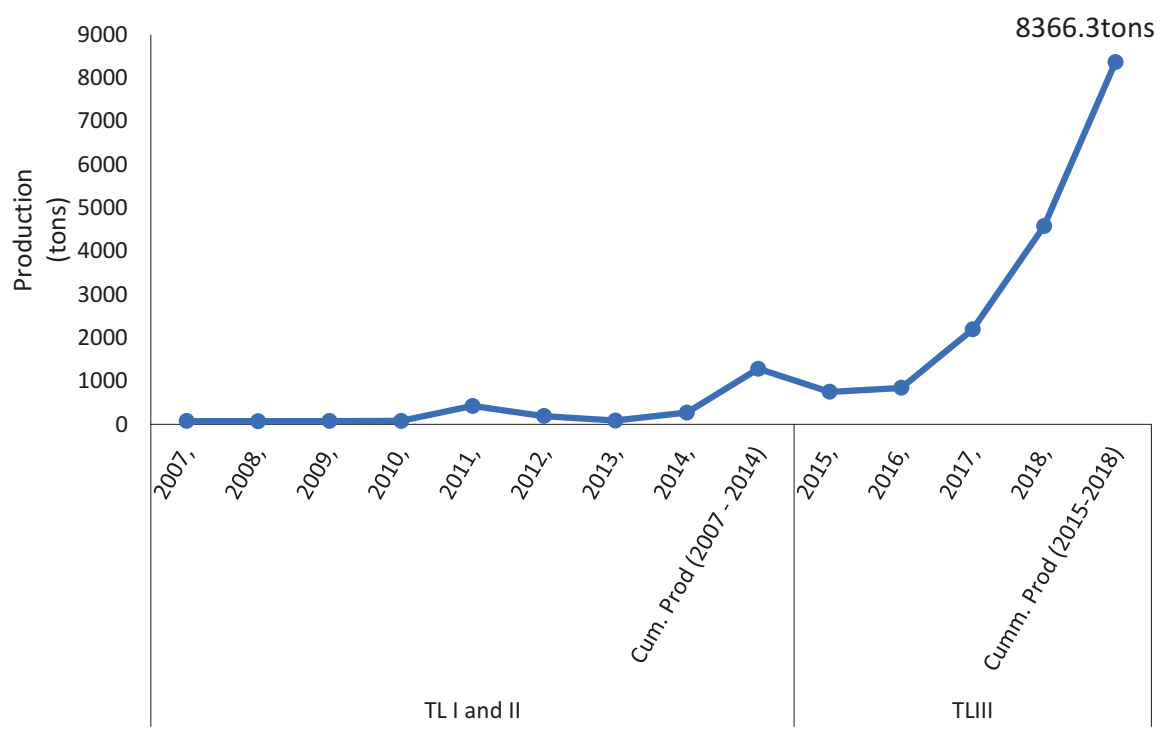

Fig. 9.2 Cowpea certified seed production in Nigeria from 2007 to 2018 
The small packs approach was extensively used; several farmers and CBOs were trained in seed packaging and are selling large volumes of quality seeds in small packs to other farmers at affordable prices. All the certified seeds produced were sold, $30 \%$ of which were sold in small packs $(1,2,5,10$, and $20 \mathrm{~kg})$, exceeding the $20 \%$ target. Marketing of seed in small packs has proven to be a handy strategy for wider impact. The strategy is convenient, enhances affordable seed access to farmers, and is an affordable means of testing new varieties with farmers. The approach also presents an opportunity for private companies to expand seed business to remote and poor, hard-to-reach women farmers.

\subsubsection{Appropriate Input and Output Marketing Strategies Identified for Male and Female Farmers}

One of the key factors to successful and sustained adoption of yield-enhancing agricultural technologies is an assured market, through which farmers can sell their production. Marketing and production are interdependent and mutually beneficial for both producers and marketers. Producers must be convinced that a remunerative market exists, particularly for "new" varieties, before they produce commercially. An attractive market prospect combines a "good" price and an assured sale. In addition, adoption and commercial production can be enhanced by the timely availability of adequate and appropriate inputs at reasonable prices.

TL-III undertook a market survey to identify input and output dealers and processors with the aim of developing an appropriate agricultural input and output marketing strategy for male and female farmers. This provided information that facilitated market links between service providers (input suppliers and dealers) and farmer groups for bulk delivery of inputs at conditions agreeable to both parties.

\subsubsection{Increased Access to and Understanding of Market Information by Male and Female Farmers in the Project Area}

Awareness of price information plays a critical role in bargaining power and competitiveness in business transactions. Agricultural markets are largely imperfect due to lack or limited access to market information, which is vital in marketing agricultural produce. Market information also assists farmers to decide the when, where, and how of their marketing strategies. It also contributes to the operational efficiency in commodity markets.

The dissemination of market prices was significant in promoting transparency in business transactions among farmers, middlemen, and processors. It strengthened the bargaining power of farmers with middlemen who are usually better informed about prices and demand prospects. As a result, farmers were better informed on developments in the agricultural markets which helped them to decide when and where to market their produce. 


\subsection{Achievements in the Areas of Access to Knowledge and Farm Advisory Services}

Significant progress was made in addressing the key problems of farm advisory service (extension, NGO, research) after membership of the MSP. Field observation revealed that most farmers now use new management practices on their fields. Most farmers now plant cowpea on ridges and practice closer spacing than in the past. A survey of farmers' field showed that farmers spray their cowpeas at least twice, with many spraying three times to control insect pests as against the past when farmers give reasons not to spray cowpeas due to lack of finance. In most of the communities where TL-III was not working, adoption of improved cowpea varieties was limited; it was restricted to those who had some contact through friends or relatives with TL-III. Of the new management practices, agro-chemicals for pest control had been widely adopted. There were, however, considerable concerns about the safe use of agro-chemicals and lack of training of contract sprayers especially in the nonTL-III areas. This concern was addressed by further sensitization and repeated training in the use of agro-chemicals in most of these areas.

The main benefits reported by farmers as the direct impact of the interventions were improved food security, improvements to people's lives, and the acquisition of additional assets. Specific indicators reported included:

- Improved food security: Increased yields, improved household nutrition with harvest lasting from one season to the next, more cowpea in the house with enough for both consumption and sale.

- Improvements in livelihood: Higher incomes, improved food availability, ability to pay school fees of children, ability to honor social commitments, and improved health. Honoring social commitments resulted in better family and community relationships, indicating building of social capital in the community.

\subsection{Achievements in the Areas of Gender Equality and Youth}

To ensure the production of high-quality seed and maintain seed standard among farmers in the project areas, the project facilitated the training of platform members in all the communities. Activities were conducted towards training of platform members across communities for cowpea production and marketing. A total of 123 trainings and short courses were held in various field agronomy aspects including quality seed production, group dynamics and management, GAPs, postharvest handling, and pest management, benefiting 20395 (m: 13 861; f: 6534) platform members (farmers, seed producers, seed companies, grain traders, researchers, extension staff, scientists, technicians, farmer organizations/CBOs, and agro-dealers), of which $32 \%$ were women have been trained.

To improve the efficiency of data and information gathering and dissemination, and technical reporting; the project facilitated the training of NARS staff, mostly 
youth, on data collection tools which are now used for effective data capturing (ODK platform) and monitoring. The project also facilitated the capacity development of local partners who are the frontlines in technology dissemination to farmers. These include extension agents from the agricultural development programs (ADP) and NARS in the participating countries. In Nigeria, a total of 15 extension staff of ADPs and three seed companies have been trained in seed certification and quality control. Partners were also trained on seed catalogue and digital seed roadmap to build their skills in planning, producing, tracking, and delivering quality seeds to smallholder farmers in Nigeria.

\subsection{Main Challenges Solved for Women}

Land tenure and other cultural issues hinder women from farming cowpea on their own. However, enlightenment campaigns and mobilization efforts by extension agents and project staff are encouraging more women to be cowpea farmers. About $30.2 \%$ of the networked farmers were women and there are indications that the number will continue to increase. The project through the MSP facilitated the introduction of two labor-saving technologies/mechanization tools (planter and thresher) to reduce drudgery especially among female farmers.

\subsection{Main Challenges Addressed for Youth}

Training on the safe use of pesticides has helped to reduce the risk of exposure to toxic chemicals during spraying. Youth in agribusiness were also trained in cowpea seed production and linked to seed packaging companies.

\subsubsection{Sustainability of Multi-Stakeholder Platforms}

TL-III's success has been built on the development of strong partnerships among MSP members. Strengthening of community-based organizations, the mainstreaming of gender combined with the use of research knowledge and proven technologies will ensure sustainability. The increased capacity of partners, particularly seed producers, to produce and market improved seed will make a significant contribution to sustainability. The linkages between community-based seed producers, seed companies, and research institutions will ensure sustainability of seed production of different classes. Similarly, strengthened linkages among farmers, market agents, and processors will ensure sustained market for the product. 


\subsection{Elements of Sustainability}

Sustainability will depend on the release of farmer-preferred cowpea varieties and promoting these varieties at scale to reach the smallholder farmers in the rural areas. That implies knowledge in product development and deployment in a challenging environment. Access to quality seeds of cowpea varieties that are adapted to the needs and production systems of farmers is essential for sustainable cowpea production. A sustainable seed system will ensue that farmers have timely access to affordable quality seeds of the most suitable cowpea varieties. Over the years, IITA has worked with NARS, research and breeding institutions, seed companies, seed enterprises, and community-based seed organizations to develop and operate a sustainable seed sector value chain. Most of the farmers trained as seed producers are still producing. There are prospects that some of these seed producers will develop into self-sustaining rural enterprises with the capacity to meet the demand for quality seed of improved cowpea varieties for farmers within and around their communities. Other elements of sustainability include private-public partnership, capacity building, and strengthening of institutions to produce and supply EGS to seed companies for production of foundation and certified seeds. Promote community bases seed production (CBSP) using out-growers scheme and linking the CPS to seed companies for seed buy-back their seed. This encouraged the CPS to produce seed in the rural area because of the ready market. The success of local seed production and local seed associations and its links to the formal seed sector may play an important role in ensuring the sustainability of increased quality seed of cowpeas.

\subsection{Steps Taken to Enhance the Sustainability of Platform Activities and Achievements after TL III}

The project facilitated the establishment and strengthening of multi-stakeholder seed delivery platforms that include stakeholders across the entire cowpea seed value chain in Nigeria. TL-III facilitated the establishment or strengthening of seven platforms across four states in Nigeria, to link actors in the cowpea value chain, avenues for training and skill enhancement were provided along with improved efficiency and effectiveness in technology development and use. The multistakeholder approach is hinged on several overarching components including partnership building, capacity development, exposure to innovative seed systems approaches, and intensifying efforts to reach the last-mile smallholder farmers with improved technologies. This innovative platform approach exposed farmers to new varieties and complementary technologies while gaining affordable access to these technologies within their proximity. 


\subsubsection{Perceptions of Stakeholders}

For many of the stakeholders interviewed, the MSP has had a positive impact on efficient seed delivery systems and has ensured the availability of quality seed of improved crop varieties which has benefited farmers particularly those at grassroot level. Others viewed information sharing between platform members as beneficial and it helped members to grow their activities together.

Some members mentioned that the MSP taught them that working together was an effective way of mutually improving their activities and income. The MSP members stated that joint activity planning had enabled them to understand that they could immediately call the service providers when there was an attack by insect pests that need to be sprayed, which they were not doing before the establishment of MSP because of the lack of connection with the service providers and input dealers. Under TL-III, contact was made on time with the service provider and the cowpea farm sprayed, thus, grain yield increased almost twofold. Through MSP meetings of farmers and traders, the farmer groups have contact with grain merchants for their products, even before harvesting; they contacted the traders in advance to find out what their needs are. This has reduced the uncertainty around product market values at harvest time, and so has contributed to improved production, as farmers can now produce with less fear as to the potential market outlet. According to other members of the MSP, cowpea seed production skills and pest management techniques have been enhanced. The IP meetings provided a forum for the exchange of information and knowledge between the diverse participants, which is crucial for networking and improving agricultural activities. The test demonstration plots were very useful in convincing many of the stakeholders to use quality seeds of new, improved cowpea varieties rather than the recycled seed of old varieties.

\subsubsection{Reflections on the Process}

The MSP has helped to foster the integration of diverse stakeholders to address a common challenge of low crop productivity in many communities in Nigeria. The process has also facilitated access to improved seed and provided information on the acquisition of other inputs and market knowledge to members. Cowpea farmers on the platform have increased their cowpea production with appreciable yield per unit area. With the representation of the various stakeholders on the platform, members are better informed on issues pertaining to the cowpea value chain. They are also familiar with how to obtain credit from financial institutions, consequently ensuring joint learning and cooperation among diverse actors to solve problems and reduce uncertainties. The MSP created opportunities for research to be demanddriven as they identify and present researchers with critical issues for research, results of which are disseminated to the target beneficiaries.

The community-based seed producers having been trained to produce quality seed at community level and are linked to private seed companies. Members of the 
MSP are actively engaged in producing and packaging cowpea seed for sale and are engaged in other operations/activities during the off-season for self-reliance.

\subsubsection{Areas to Focus on in the Future}

- Work with the private sector to further strengthen the seed system to truly meet the needs of the smallholder farmers especially women in Nigeria to ensure women farmers have equal access to improved seeds.

- Generate gender-responsive demand through linkages and innovative public-private partnerships.

- Ensure that there is an efficient cowpea market-led seed industry for the production and distribution of high-quality cowpea seed that is accessible and affordable for the majority of farmers.

- Engage the private and public sectors, particularly the agricultural universities, to boost the production and availability of EGS to meet market demand. This will be achieved by strengthening the technical and business acumen of those involved.

Mechanization of cowpea production will be promoted to reduce drudgery and ease production. More local partners will be engaged in the fabrication and maintenance of more efficient cowpea pre- and postharvest machine technologies in the rural areas. The adoption of such labor-saving technologies will make cowpea production more attractive to the youth who can produce foundation and certified seeds. Facilitate a stronger linkage between the public sector, private seed companies, agro-input service providers, and community-based seed producers. Communitybased seed production is promising for sustainable seed production, to ensure the continuous availability of quality seed to farmers in local communities. Other innovations to focus on will include increasing farmer access to inputs such as fertilizer and agro-chemicals and continued linking of farmers with financial institutions. Involving NARS partners and seed companies in the business of producing early generation seeds to meet the growing demand for certified seed. Crop modeling for decision-making on productivity of cowpea in different ecological zones.

Finally, engagement of the private sector for massive awareness campaign at the community, local government, state, and national levels, to sensitize farmers on the availability of new varieties, and the benefits of using quality seed of improved cowpea varieties through demonstration and other complementary technologies.

\subsubsection{Lessons Learned}

- Engagement of community-based seed producers increased the supply of quality seeds of improved cowpea varieties in the remote areas. Through this arrangement, a large number of farmers were reached. 
- Resource-poor farmers are ready to adopt new improved cowpea varieties if they possess end-user characteristics.

- An efficient seed system for delivering varieties must be linked to the commodity value chain. The developed grain markets are an obvious driver of seed demand through which the need for productivity is justified.

- The multi-stakeholders approach enhances efficiency and effectiveness in technology promotion. Diversification of seed sources by linking formal and informal seed systems to enhance seed access to smallholder farmers especially those in remote areas.

- Using smaller seed packs as a marketing approach has the potential to reach hundreds of thousands of farmers quickly, including women. The sale of small packs has helped to expand the use of certified seeds. It has also given farmers the opportunity to experiment with new varieties at minimum risk.

- Well-structured, in-country review and planning meetings will provide stakeholders with the opportunity to understand procedures for better implementation of project activities.

\section{References}

FAOSTAT (2017) FAOSTAT, Statistical data base. Food and Agriculture Organization of the United Nations, Rome, Italy

Tukahirwa J, Mol A, Oosterveer P (2013) Comparing urban sanitation and solid waste management in East African metropolises: the role of civil society organizations. Cities 30:204-211. https://doi.org/10.1016/j.cities.2012.03.007

Open Access This chapter is licensed under the terms of the Creative Commons Attribution 4.0 International License (http://creativecommons.org/licenses/by/4.0/), which permits use, sharing, adaptation, distribution and reproduction in any medium or format, as long as you give appropriate credit to the original author(s) and the source, provide a link to the Creative Commons license and indicate if changes were made.

The images or other third party material in this chapter are included in the chapter's Creative Commons license, unless indicated otherwise in a credit line to the material. If material is not included in the chapter's Creative Commons license and your intended use is not permitted by statutory regulation or exceeds the permitted use, you will need to obtain permission directly from the copyright holder.

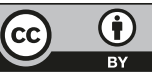

